\title{
Development of Dust Concentration Model using Artificial Neural Networks
}

\author{
K.V. Nagesha, Garimella Raghu Chandra
}

\begin{abstract}
The Minerals extraction from the earth in various open cast mines virtually leads to an enormous amount of dust is releasing to environment. Due to dust dispersed in to atmospheric, various problems occur like health related problems, vegetation problems and chances of accidents of heavy weight moving vehicles on the road. To get permission from EIA (Environmental Impact Assessment) for extending projects and maintaining the green belt environment surrounding of mine models are necessary to determine particulate matters (PM) in the environment. To predict dust emission and concentration values from blasting activity, Artificial Neural Network (ANN) method is used. To train network 'Trainlm' algorithm is used, the coefficient of determination value for emission model is 0.99 and for concentration model 0.97 respectively. The 'Trainlm' algorithm is the suitable method for predicting the dust emission values and concentration values produce by blasting activity.
\end{abstract}

\section{INTRODUCTION}

The removal of ore from earth in various opencast mines they have several mining activities are under go. Dust is produce in each every stage of mining activity. Among different activities, blasting is one of the most important activity in the mine site. Various researchers have done assessment and quantifying of dust emission for different activities, but the USEPA has neglected to determine empirical formula for quantifying of dust emission by blasting activity (USEPA 1991). The various researcher were developed various mathematical tools to predict dust emission and for assessment of environmental impacts. Those tools were developed based on their physicomechanical properties and based on their atmospheric conditions. (Surendra Roy et al., 2010).

S.K. Chaulya et al. and Ghouse, developed various mathematical linear models for various activities but they did not developed any tool related to dust emission from blasting operation. S. Roy et al. developed a model for quantifying dust emission and concentration from blasting operation in coalmines using Artificial Neural Network method and Regression analysis. In this research, an attempt has been made to develop mathematical model to predict dust emission and concentration from three granite quarries using a statistical tool called ANN techniques from Mat lab R2013. The different particle size of dust produced by various activities in the mine is dispersed in to the atmosphere (Mrinal K. Ghose and Majee, 2007). The particle size more than 10micron (PM10) is easily arrested during inhalation process, the PM10 can easily settle down

Revised Manuscript Received on 14 September, 2019.

K.V. Nagesha, Sr. Assistant Professor, Department of Mechanica Engineering, Madanapalle Institute of Technology \& Science, Madanapalle, Andhra Pradesh, India.(Email: knagesha@gmail.com)

Garimella Raghu Chandra, Associate Professor, Department of Electrical and Electronics Engineering, Methodist College of Engineering and Technology, Hyderabad, Telangana, India. (Email: raghuchandhra@gmail.com) on the respiratory system, but PM2.5 can join with the blood through an alveolus in the lungs system. Exposing to such an environment may cause lung diseases. The larger particles may affect nose, throat and cause irritation to eyes. (ILO working group, 1995).

\section{FIELD INVESTIGATIONS}

The field investigations were done in total three granite quarries. Namely, mine-1, mine-2 and mine-3 (Figure-1). In all three quarries, the benching method was adapted to remove the granite stones from the earth. Typical broad views of three quarries and blasting activity at mine-1 shown in Figure 1. In these quarries, the rocks were broken by drilling and blasting. The Wagon drills are having diameter $115 \mathrm{~mm}$ was used for drilling blast holes at mine-2, similarly jackhammers are having 32 and $38 \mathrm{~mm}$ drill bit diameters were used at mine- 3 and mine- 1 .

In mine-2. total 23 sets of values were collected for dust concentration model range from $1235-741 \mu \mathrm{g} / \mathrm{m}^{3}$. In mine- 1 , 20 samples of dust concentration values range from 789-420 $\mu \mathrm{g} / \mathrm{m}^{3}$ were collected. Similarly, from mine-3 total 15 samples collected for dust concentration range from 835-295 $\mu \mathrm{g} / \mathrm{m}^{3}$. To develop mathematical model both mine- 2 and mine-1 dust monitored values were used and third mine data was used for validation.

\section{METHODOLOGY}

To monitor dust dispersion and emission from blasting operation, four respairable instruments and two ambient point samplers were used. After the completion of blast holes patterns, the explosives are filled and closed. A chemical reaction in the explosive occurs and enormous of energy released, which causes breaks in the rocks, and so virtually large amount of dust dispersed in to the atmospheric. The dust was monitored at different distances with respect to downwind from source of blasting activity. Initially to know the background concentration, one instrument was kept at up wind direction. Dust dispersion coefficients are determined based on downwind distance with respect to wind velocity from Giffored Pasquils formula. The metrological parameters are taken from metrological station, which was installed near to mine. 


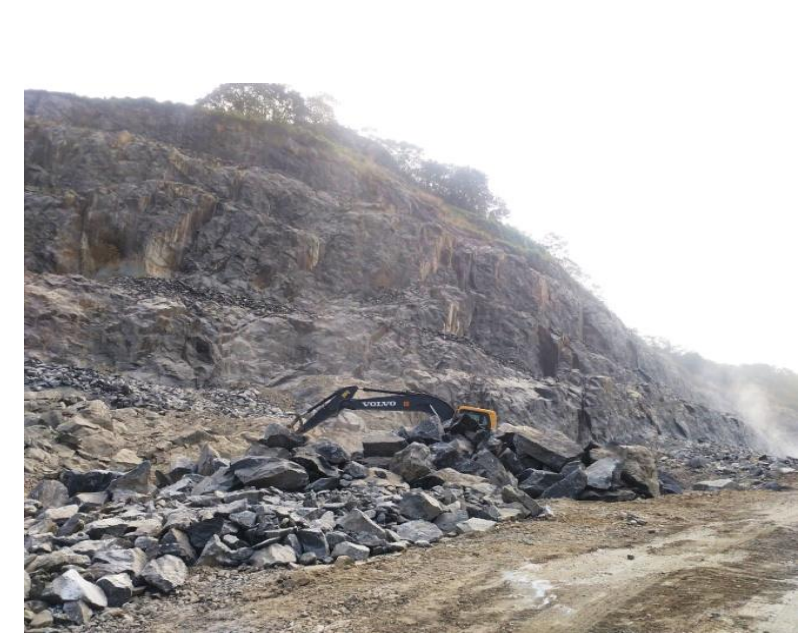

(a) Mine-1

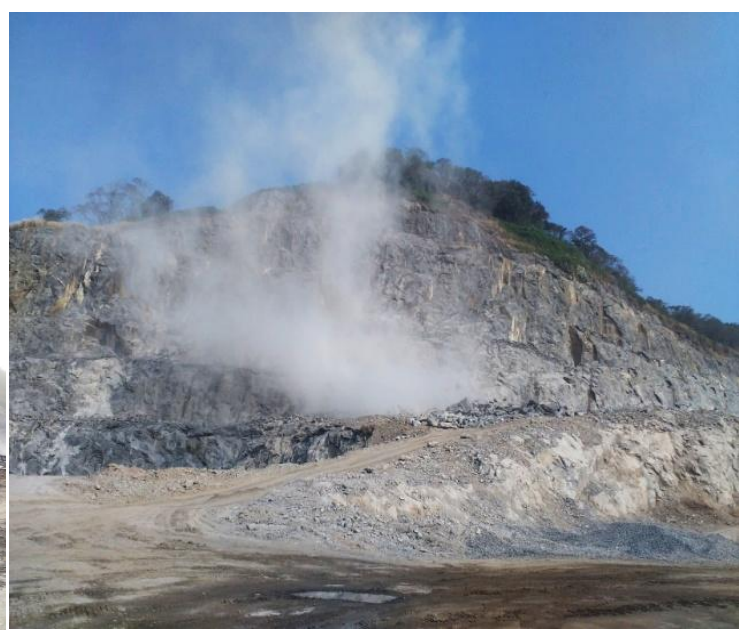

(b) Mine-1

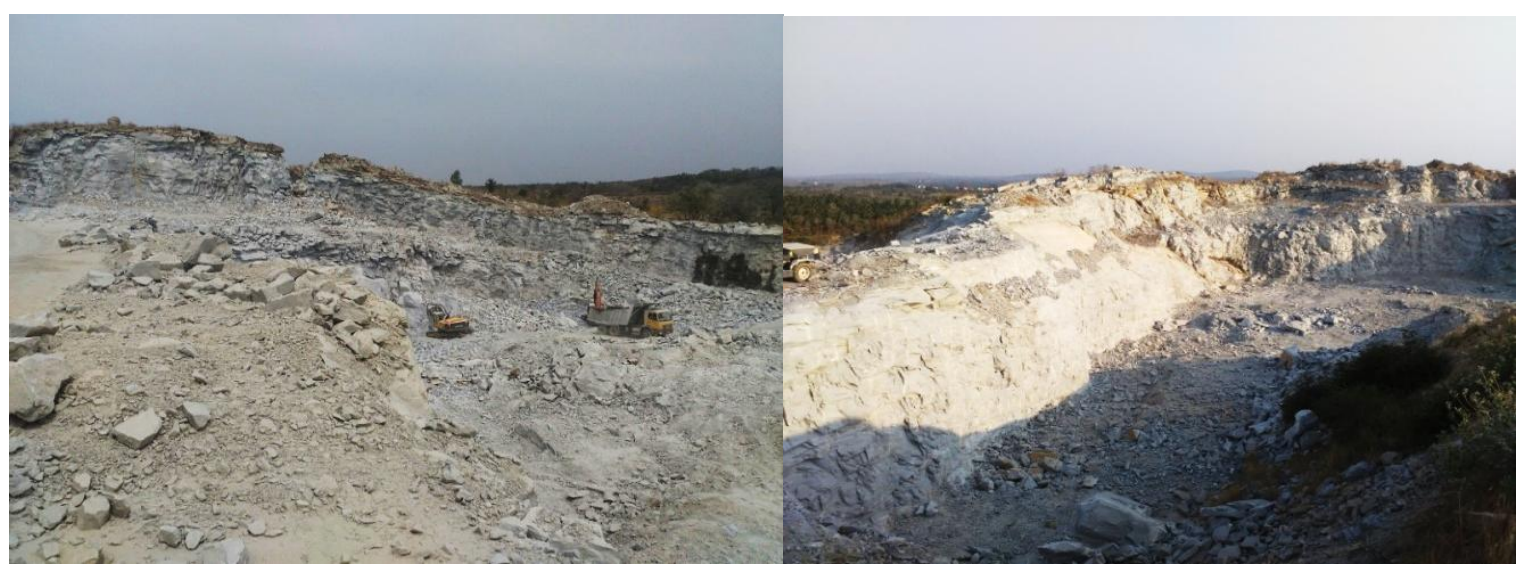

(c) Mine-2

(d) Mine-3

Figure 1 Typical broad view of three granite quarries

\subsection{Determination of Rock Properties}

At the end of the dust sampling, some rock samples were collected and determined various physico-mechanical properties in laboratory according to ISRM suggestion methods. The various properties are like density, moisture content, hardness and compressive strength (Protodyakonov's Strength Index).

\section{Density}

Initially a container with some amount of water was taken. The difference of water level was observed by taking the value before and after putting the rock sample into the container. The obtained difference of water level was used to find the volume of rock sample and the following formula is used to find the density of the rock mass

Density $=\mathrm{m} / \mathrm{v}$

where,

$\rho=$ density, gm/cc

$\mathrm{m}=$ mass, gm

$\mathrm{v}=$ volume, $\mathrm{cc}$

\section{Moisture content}

To know the moisture content present in the rock sample the following method was used. It is expressed in terms of percentage. The following formula was used to determine the moisture content.

Moisture content $=($ Mass of water content $/$ Dried sample weight)*100

\section{Compressive strength}

Compressive strength of rocks were determined using ISRM suggested methods. The compressive strength of granite rocks were determined indirectly using Protodyakanov's strength index.

\section{Schmidt rebound hardness number}

Schmidt Rebound Hardness number was determined according to ISRM (International Society for Rock Mechanics) suggested methods. The procedure involves, a hammer released by means of a spring that indirectly influences against the rock surface through a plunger; the rebound distance of the hammer is read directly from the numerical scale that ranges from 10-100. Twenty rebound values obtained from a single impact separated by at least a plunger diameter was recorded and the average of upper ten values was taken as rebound hardness value.

Published By: 


\section{RESULTS AND ANALYSIS}

To develop mathematical models for dust emission and concentration from blasting activity, two granite quarries data were used and for validation, third granite quarry data was used. Total 43 sets of values were used for model development and 15 sets of values were used for validation.

Development of dust prediction models by Artificial Neural Network (ANN) method

To develop model from ANN method used software called Mat lab R2013. It is a statistical tool used for various environmental related problems. This provides ANN an advantage over other statistical and conventional prediction methods such as logistic regression and numerical methods, in which nonlinear interactions among variables must be modeled in explicit functional form. Initially to train the network feed forward neural network with back propagation algorithm was used. In this type of method, the feedback loops are absent and the output error was reduced by adjustment of weights in the network.

The analysis was done for different combinations of hidden layers and the network showing the least root mean square error was selected here. The input data has been divided into two types like training data is used to train the network and output data is used to implement of the early stopping technique because to avoid over fitting to the training data.

To develop dust prediction model, 43 sets of data for concentration model was used. Network learning was done by adjusting synaptic weights of multilayer network to known output. Training can be stopped when performance of the model on output data set gives minimum error. Testing data set stimulates actual forecasting of data samples. A typical architectures and input variables are shown in Figure 2 and Figure 3. To train network some parameters were used in neural network method.

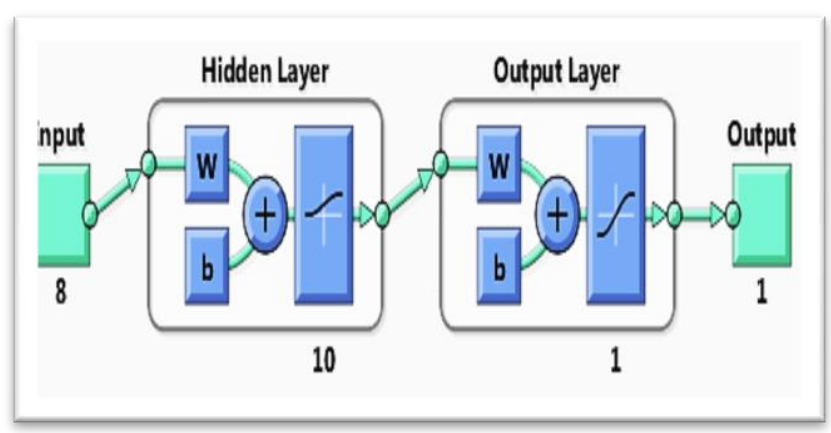

Figure 2 Typical Architecture of Input Variable and Output Variable for Emission Model

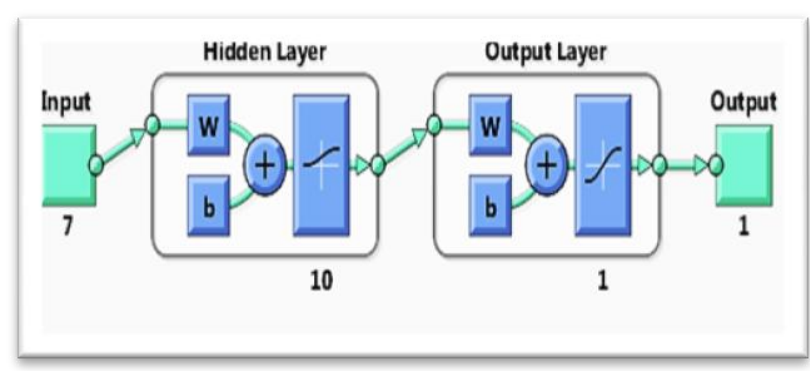

Figure 3 Typical Architecture of Input Variable and Output Variable for Concentration Model
Figures 4 and 5 shows correlation between actual field measured values with predicted values in case of Emission rate and Concentration.

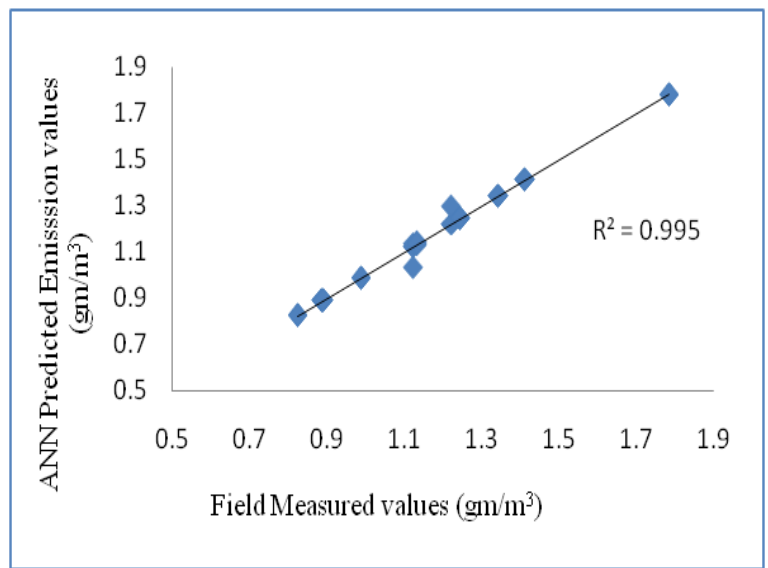

Figure 4 ANN Predicted values VS Field Measured Emission Values

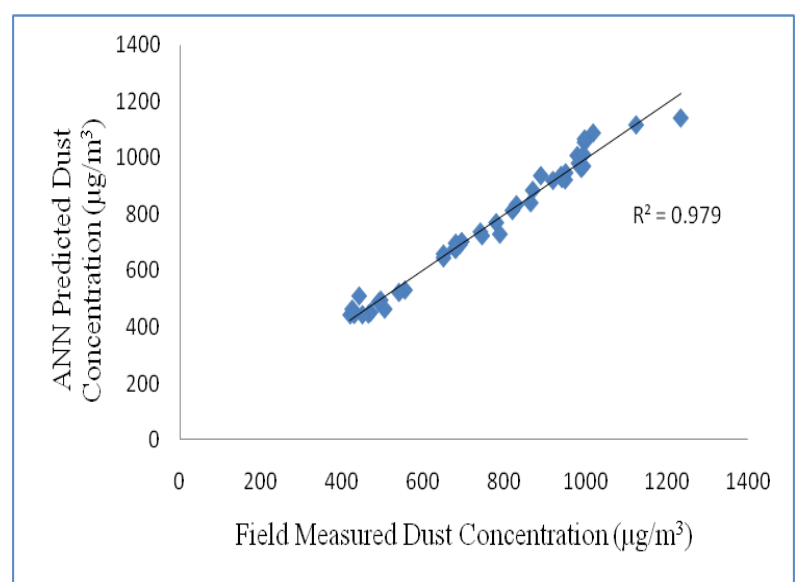

Figure 5 ANN Predicted values VS Field Measured Concentration Values

The best fit of the model was assessed using the $\mathrm{R}^{2}$ value, the $\mathrm{R}^{2}$ value obtained for emission equation is 0.99 and for concentration is 0.97 , which shows good correlation (Figures 6 and 7).

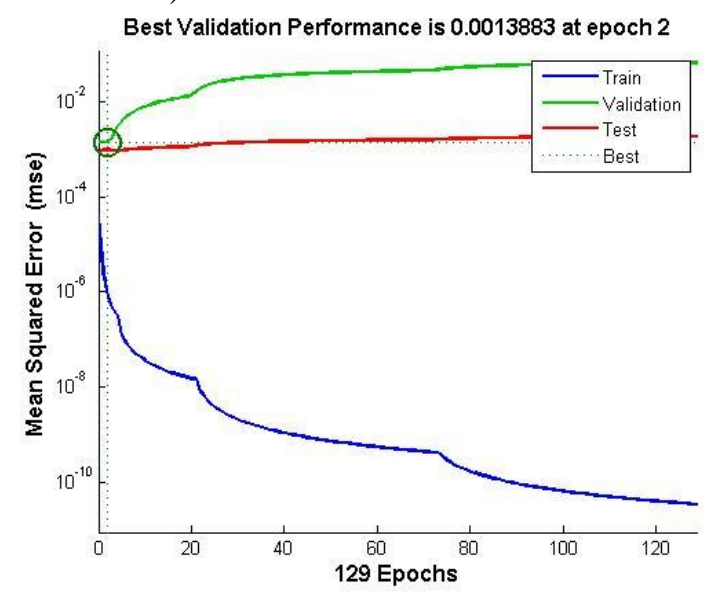

Figure 6 Performance of ANN Emission model for training and validation data for PM10

Published By: 


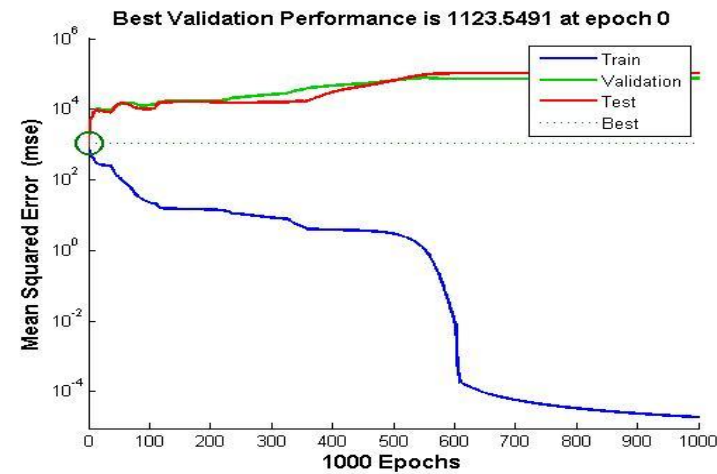

Network was trained using 'Trainlm' algorithm was used for training the input data. Network showing time taken for training data, number of epochs and mean square error for concentration model and emission model (Tables 1 and 2).

Figure 7 Performance of ANN Concentration model for training and validation data for PM10

Table 1 Parameters used in neural network for emission model and concentration model

\begin{tabular}{|c|c|c|}
\hline Training Parameters & Emission model & Concentration model \\
\hline Network type & Feed forward back propagation & Feed forward back propagation \\
\hline Training function & TRAINLM & TRAINLM \\
\hline Adaptive learning function & LEARNGDM & MSE \\
\hline Performance function & MSE & 2 \\
\hline Number of layers & 2 & 10 \\
\hline Number neurons in hidden layer-1 & 10 & LOGSIG \\
\hline Transfer function in hidden layer & LOGSIG & TANSIG \\
\hline Transfer function in output layer & TANSIG & \\
\hline
\end{tabular}

Table 2 Performance of training algorithm for emission values and concentration values

\begin{tabular}{|c|c|c|c|c|c|}
\hline & $\begin{array}{c}\text { Training } \\
\text { algorithm }\end{array}$ & $\begin{array}{c}\text { Network } \\
\text { architecture }\end{array}$ & $\begin{array}{c}\text { Number of } \\
\text { epochs }\end{array}$ & $\begin{array}{c}\text { Time taken for } \\
\text { convergence (sec) }\end{array}$ & $\begin{array}{c}\text { Mean square } \\
\text { error }\end{array}$ \\
\hline Emission model & Trainlm & $8: 10: 1: 1$ & 00 & 01 & 0.0013883 \\
\hline Concentration model & Trainlm & $7: 10: 1: 1$ & 02 & 06 & 1123.6490 \\
\hline
\end{tabular}

\section{CONCLUSIONS}

To develop models by ANN method, total 42 sets of values used for emission model and concentration model. The parameters are considered for emission model are like diameter, area of blast, depth of hole, explosive quantity, moisture content, density, compressive strength and rebound harness number. Similarly for concentration model the input parameters are like distance, wind speed, temperature, relative humidity, sigma $\mathrm{z}$, sigma $\mathrm{y}$, and emission value are considered.

The two models developed by ANN method the following conclusions are drawn.

- The models were developed by using Feed forward neural network and back propagation algorithm was used

- The network was trained by 'Trainlm' algorithm was used and the coefficient of determination for emission model is 0.99 and for concentration model is 0.97 shows good correlation

- The MSE for emission model is 0.0013883 and for concentration model 1123.6490

To predict dust concentration values for blasting activity the 'Trainlm' algorithm is more suitable.

\section{REFERENCES}

1. Cole, C.F., and Zapert J.G., (1995). Air quality dispersion model validation at Three Stone Quarries. National Stone Association, 14884.

2. Surendra Roy, Govind Raj Adhikari, and Trilok Nath Singh. (2010). Development of Emission Factors for Quantification of Blasting Dust at Surface Coal Mines. Journal of Environmental Protection. V-1, pp 346-361

3. S. K. Chaulya, M. Ahmad, R. S. Singh, K. Bandopadhyay, C. Bondyopadhay and G. C. Mondal. (2003). Validation of Two Air Quality Models for Indian Mining Conditions. Environmental Monitoring and Assessment. - V-82, pp 23-43.

4. S. Roy, G.R. Aadhikari, T.A. Renaldy and A.K. Jha. (2011). Development of Multiple Regression and Neural Network Models for Assessment of Blasting Dust at a Large Surface Coal Mine. Journal of Environmental Science and Technology V-4, pp 284-301

5. Mrinal, K., Ghose, and Majee S. R., (2007). "Characteristics of hazardous air borne dust around an Indian surface coal mining area." Environmental Monitoring and Assesment.Volume130. pp 17-25.

6. U. S. Environmental Protection Agency, Review of Surface Coal Mining Emission Factors. Emission Factor and Inventory Group, Research Triangle Park, NC 27711, July 1991. 